\title{
A Comparison of Immunoglobulin G-Containing High-Molecular-Weight Complexes Isolated from Children with Juvenile Rheumatoid Arthritis and Congenital Human Immunodeficiency Virus Infection
}

\author{
JAMES N. JARVIS, MADONNA IOBIDZE, HEIDE TAYLOR, \\ JANELLE DEJONGE, AND SANDRA CHANG \\ Division of Immunology/Rheumatology. Wayne State University School of Medicine and \\ the Children's Hospital of Michigan, Detroit, Michigan 48201
}

\begin{abstract}
Circulating immune complexes have been described in both juvenile rheumatoid arthritis and in AIDS. We isolated high-molecular-weight complexes from plasma of children with juvenile rheumatoid arthritis and congenital human immunodeficiency virus infection by sequential gel filtration followed by affinity chromatography on protein A-Sepharose. We demonstrate that 1 ) mixed IgG-, IgM-, and IgA-bearing immune complexes can be found in both juvenile rheumatoid arthritis and congenital human immunodeficiency virus infection and 2) complexes isolated via affinity chromatography on protein A-Sepharose do not have detectable $\mathrm{C} 4$ but activate the classic complement pathway in vitro. (Pediatr Res 34: 781-784, 1993)
\end{abstract}

\section{Abbreviations}

JRA, juvenile rheumatoid arthritis HIV, human immunodeficiency virus RF, rheumatoid factor

CIC, circulating immune complex

NHS, normal human serum

The presence of complement-fixing $\mathrm{CIC}$ has been described in both JRA (1) and congenital HIV infection (2). Although both groups of patients also have elevated levels of complement activation fragments in plasma $(2,3)$, there is no correlation between either the presence or level of CIC, as detected by ELISA with solid-phase anti-Clq and anti-C3d antibodies, and levels of complement activation fragments in either of these diseases. Thus, the exact nature of the interaction between complement and CIC in these diseases remains unknown.

This lack of correlation between plasma complement activation fragments and immune complexes has caused us to question the origin of the complement-binding immune complexes seen in JRA and congenital HIV infection (3). Clues about the origin of these complexes might be derived from a better understanding

Received May 20, 1993; accepted August 3, 1993.

Correspondence: James N. Jarvis, Assistant Professor of Pediatrics, Division of Immunology/Rheumatology, Wayne State University School of Medicine and the Children's Hospital of Michigan, 3901 Beaubien Blvd., Detroit, MI 48201.

Supported by the Children's Hospital of Michigan Research Endowment Fund Parents Promoting Arthritis Research for Children (PPARC), and the Wayne State University Alumni Association, which provided a summer research fellowship for one of the authors (J.D.) of their composition and biologic behavior. The studies described here were therefore done in an effort to determine 1 ) the composition of high-molecular-weight complexes isolated from children with JRA and congenital HIV infection and 2) their ability to activate complement in vitro via either the classic or alternative pathways.

\section{MATERIALS AND METHODS}

Patients. Children attending either the rheumatology or HIV clinic at the Children's Hospital of Michigan were subjects of this study. Children with JRA all had the polyarticular form of the disease as defined by accepted criteria (4). One child had IgM-RF detected by latex agglutination tests. The other three had IgM-RF detectable by ELISA as previously described (5). The diagnosis of HIV infection was established by the persistence of HIV antibody, confirmed by Western blot, beyond the age of 18 mo in children with supportive clinical and laboratory findings as previously described (2).

Children with JRA ranged in age from 7 to 16 y (mean \pm SD $11 \pm 3 \mathrm{y}$ ). Disease duration ranged from one month to $5 \mathrm{y}$ (mean $3.5 \pm 1.7 \mathrm{y}$ ). Children with congenital HIV infection ranged in age from 23 to $48 \mathrm{mo}$ (mean $35 \pm 10 \mathrm{mo}$ ). Controls consisted of a single HIV-exposed, seroreverted child born to an HIV-infected mother, a child referred for recurrent upper respiratory infections subsequently shown to have normal immunologic function (including normal immunoglobulin and IgG subclass levels), and four healthy children from the General Pediatrics clinic.

All children with JRA were receiving nonsteroidal anti-inflammatory drugs at the time of study. In addition, one child was taking weekly oral methotrexate, $5.0 \mathrm{mg} / \mathrm{wk}$, and one was taking oral gold, $6.0 \mathrm{mg} / \mathrm{d}$. All children with HIV infection were taking zidovudine, $9.0 \mathrm{mg} / \mathrm{kg} / \mathrm{d}$.

Blood was drawn into sterile, heparinized tubes and placed immediately on ice. Plasma was separated from red cells by centrifugation and stored at $-70^{\circ} \mathrm{C}$ until used.

Proteins and antibodies. Purified human IgG, IgM, and IgA, which were used as positive controls for Western blots, were purchased from Sigma (St. Louis, MO). Polyclonal rabbit IgG anti-human IgG, IgM, and IgA, and horseradish peroxidaseconjugated goat anti-rabbit IgG were purchased from Sigma.

Buffers. Solubilizing buffer for SDS-PAGE consisted of 0.25 M Tris, $10 \%$ SDS, $2 \%$ glycerol, and $5 \% \beta$-mercaptoethanol. Transfer buffer for Western blotting consisted of $20 \mathrm{mM}$ Tris, $150 \mathrm{mM}$ glycine, $0.1 \%$ SDS, $20 \%$ methanol, pH 8.0.

Chromatography media. Sephacryl-300 was obtained from 
Pharmacia (Uppsala, Sweden). Protein A immobilized on cyanogen bromide-activated Sepharose was obtained from Sigma.

Isolation of high-molecular-weight IgG-containing complexes from JRA and HIV plasma. JRA and HIV plasma samples were screened for the presence of complement-fixing immune complexes by ELISA using solid-phase MAb to Clq and C3d as previously described (3). Plasma was then diluted 1:20 and placed on a column containing Sephacryl-300 equilibrated with PBS. Absorbance of the eluate was monitored at $280 \mathrm{~nm}$ and the first eluted peak collected and saved. The material from this highmolecular-weight fraction was then passed over a column containing Protein A-Sepharose equilibrated with PBS. The column was washed thoroughly with PBS and the bound protein eluted with $0.1 \mathrm{M}$ glycine, $\mathrm{pH}$ 2.5. Fractions with $\mathrm{OD}$ higher than background were saved (Fig. 1). This material was then dialyzed against PBS and concentrated by ultrafiltration to $0.5-1.0 \mathrm{~mL}$ after $300 \mu \mathrm{L}$ were saved for rheumatoid factor assays (see below). Protein concentration of the fractions was then determined by the method of Lowry et al. (6).

$S D S-P A G E$. After dialysis, the IgG-containing high-molecularweight complexes were solubilized in $5 \times$ solubilizing buffer and heated at $90^{\circ} \mathrm{C}$ for $2 \mathrm{~min}$. The complexes were then subjected to SDS-PAGE using the method of Laemmli (7). Gels were stained with Coumassie blue and the visualized protein bands compared with $\operatorname{IgM}, \operatorname{IgG}, \operatorname{IgA}$, and molecular weight standards applied to the same gels.

Western blot analysis of immunoglobulin content from IgGcontaining high-molecular-weight fractions. Thirty $\mu \mathrm{L}$ of the complexes were subjected to SDS-PAGE as described above. The gels were then equilibrated with transfer buffer and the proteins electrophoretically transferred to nitrocellulose. The nitrocellulose membranes were then incubated with $1.0 \%$ powdered milk in PBS (blocking buffer) at room temperature for $1 \mathrm{~h}$ and then at $4^{\circ} \mathrm{C}$ overnight. The membranes were washed thoroughly with deionized distilled water, then incubated $1 \mathrm{~h}$ with rabbit antihuman IgG, IgM, or IgA diluted 1:100 in blocking buffer. After incubation with antibody, the membranes were again washed with deionized distilled water and incubated at room temperature for $1 \mathrm{~h}$ with HRP-conjugated goat anti-rabbit IgG diluted 1:100 in blocking buffer. The membranes were again washed with deionized distilled water and the colorimetric reaction was developed with 4-chloro-1-napthol (CN), 3,3'-diaminobenzidine/ urea (Sigma). Results were compared with positive controls consisting of IgG, IgM, or IgA.

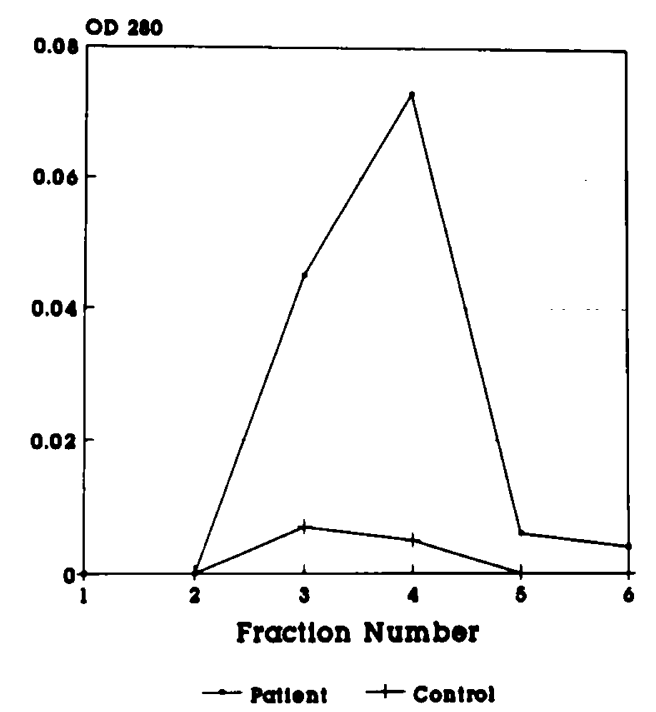

Fig. 1. Elution profile of complexes eluted from a column containing $3.0 \mathrm{~mL}$ of protein A-Sepharose by $0.1 \mathrm{M}$ glycine, $\mathrm{pH} 2.5$. Three-mL fractions were collected and the OD of each fraction was measured at OD 280. Small amounts of protein are eluted from fractions number 2 and 3. Results from a patient with congenital HIV infection are compared with results obtained from an uninfected control.
ELISA assay for IgA, IgM, and IgG RF. The rheumatoid factor assays were adapted from an assay that we have previously described (2). In brief, multiwell plates were coated with human IgG (or, for the IgG-RF assay, rabbit IgG), $10 \mu \mathrm{g} /$ well. One hundred $\mu \mathrm{L}$ of each of the high-molecular-weight fractions were then added in triplicate to the wells and incubated at $37^{\circ} \mathrm{C}$ for 4 $h$ (the $100 \mu \mathrm{L}$ of the high-molecular-weight fractions used for the RF assays were taken before concentrating the fractions for immunoblotting). The plates were washed and incubated with alkaline phosphatase-conjugated goat anti-human IgG, IgM, or IgA at $37^{\circ} \mathrm{C}$ for $4 \mathrm{~h}$. The plates were then washed and the colorimetric reaction was developed with p-nitrophenylphosphate. After the reaction was stopped with $2 \mathrm{~N}$ sodium hydroxide, plates were read at $405 \mathrm{~nm}$. Results were compared with a standard curve derived from four high-molecular-weight fractions prepared on the S-300 column (but not subjected to further purification on protein A-Sepharose) from plasma samples from the negative controls. Results greater than 2 SD from the mean of the controls were considered positive.

Complement activation studies. Ten $\mu \mathrm{g}$ of the high-molecular weight complexes were added to $30 \%$ normal human serum in PBS (final volume $0.5 \mathrm{~mL}$ ). The reaction mixtures were then incubated at $37^{\circ} \mathrm{C}$ for $1 \mathrm{~h}$, and any further complement activation was stopped immediately by adding an equal volume of ice-cold PBS-Tween with $20 \mathrm{mM}$ EDTA. Samples were then assayed for levels of either complement fragment $\mathrm{Bb}$ (formed principally during alternative pathway activation) and $C 4 d$ (produced during classic pathway activation) using previously described ELISA assays (3). Controls consisted of $30 \%$ NHS on ice ("zero time") and $30 \%$ NHS incubated at $37^{\circ} \mathrm{C}$ for $1 \mathrm{~h}$ ("thermal control"). Positive controls consisted of $10 \mu \mathrm{g}$ of soluble BSA-anti-BSA immune complexes formed at $2 \times$ antigen excess and added to $30 \%$ NHS and incubated as above.

\section{RESULTS}

Purification of high-molecular-weight IgG-containing fractions. Figure 2 shows representative polyacrylamide gel of high-molecular-weight IgG-containing fractions from patients with congenital HIV infection and JRA. Prominent $65-\mathrm{kD}$ bands are seen on Coumassie-stained gels for both HIV and JRA patients. These bands corresponded with IgM on immunoblotting (see below). Such complexes were also isolated from two HIV-infected children with negative ELISA assays for immune complexes using anti-Clq and $\mathrm{C} 3 \mathrm{~d} \mathrm{MAb}$ (patients 9 and 10, Table 1). Negative controls had no visible bands on Coumassie-stained gels.

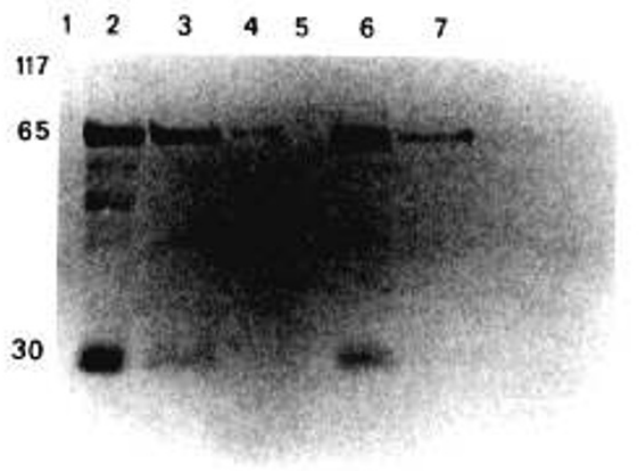

Fig. 2. Coumassie-stained $10 \%$ polyacrylamide gel from immune complex preparations from HIV-infected children and children with JRA. Lane 1, negative control. Lanes 2-4, immune complexes from children with congenital HIV infection (patients 5,8 , and 6 , respectively). Lane 5, negative control. Lanes 6 and 7, complexes from children with JRA (patients 7 and 2, respectively). Prominent $65-\mathrm{kD}$ bands seen in all patients corresponded with immunoblots for IgM heavy chain (Fig. 3). The 50-kD bands seen in lanes 2 and 3 correspond with IgG heavy chain. Specific identification of the other bands was not undertaken. 
Table 1. Analysis of high-molecular-weight complexes from children with JRA and congenital HIV infection*

\begin{tabular}{|c|c|c|c|c|c|c|c|}
\hline Patient & Diagnosis & $\mathrm{IgG}$ & IgM & $\operatorname{Ig} A$ & IgG-RF & IgM-RF & IgA-RF \\
\hline 1 & JRA & + & + & Weak & - & + & + \\
\hline 2 & JRA & + & + & + & + & + & + \\
\hline 3 & JRA & + & + & + & + & + & + \\
\hline 4 & JRA & + & + & Weak & - & + & + \\
\hline 5 & HIV & + & + & + & + & + & + \\
\hline 6 & HIV & + & + & Weak & ND & ND & ND \\
\hline 7 & HIV & + & + & + & ND & ND & ND \\
\hline 8 & HIV & + & + & + & - & + & - \\
\hline 9 & HIV & Weak & + & + & ND & ND & ND \\
\hline 10 & HIV & + & + & Weak & - & + & - \\
\hline
\end{tabular}

* ND, not done.

In addition to the prominent $65-\mathrm{kD}$ band, additional bands at approximately 60,50 , and $45 \mathrm{kD}$ are seen in patient 2 ; the 45 $\mathrm{kD}$ band is also seen in patients 3 and 6 . The 50-kD band corresponds to IgG heavy chain on immunoblotting. Current investigations in our laboratory are aimed at identifying the other bands in these complexes. The $30-\mathrm{kD}$ band seen in patients 2,3 , 6 , and 7 may represent immunoglobulin light chain (molecular mass $=25 \mathrm{kD}$; the $10 \%$ minigels used in these studies may not be efficient at resolving molecular masses to within $5 \mathrm{kD}$ if large amounts of protein are present).

Immunoblotting for IgG, IgA, and IgM. Results from Western blots for IgG, IgA, and IgM are shown in Figure 3 and Table 1. All Western blots from children with JRA and HIV infection were positive for IgG by immunoblotting (however, the blot for patient 9 was weak; Table 1). This was to be expected in view of the method used for their purification: the binding to protein ASepharose. In addition, strongly positive bands for IgM were seen in high-molecular-weight material from all six HIV-infected children and all four children with JRA. Strongly positive blots for IgA were seen in four of six children with HIV infection (and weaker blots were seen in the other two), whereas two of the four children with JRA had strongly positive blots for IgA and the other two had weakly positive blots.

ELISA for C4d. C4d assays were performed on all 10 highmolecular-weight complex preparations. None of the high-molecular-weight fractions contained C4d at levels $\geq 0.050 \mu \mathrm{g} / \mathrm{mL}$, the limits of the ELISA.

$R F$ activity in immune complexes. Sufficient material was available to perform RF assays on seven of the 10 immune complex preparations (three from children with HIV infection and four from children with JRA; Table 1). IgM-RF activity was detected in all the immune complex preparations. In addition,

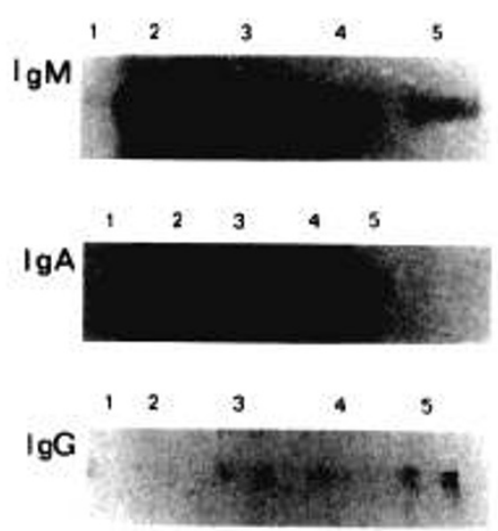

Fig. 3. Immunoblotting for IgM, IgA, and IgG: representative Western blots of immune complex preparations from HIV-infected children and children with JRA. Lane 1, negative control. Lanes 2 and 3, complexes from children with HIV infection (patients 9 and 7 , respectively). Lanes 4 and 5 , complexes from children with JRA (patients 4 and 1 , respectively).
IgA-RF were detected in all JRA immune complex preparations and in one of the three HIV preparations. IgG-RF activity was detected in two of the four JRA preparations and one of the three HIV preparations.

Complement activation experiments. Figure 4 summarizes the results of complement activation experiments, which were performed on nine of the 10 immune complex preparations. Highmolecular-weight complexes from both HIV-infected children and children with JRA activated the classic complement pathway as efficiently as model BSA-anti-BSA immune complexes formed at $2 \times$ antigen excess. The exception was the high-molecular-weight fraction from a single child with congenital HIV infection who was negative for immune complexes by the anti$\mathrm{Clq}$ and anti-C3d assays. Incubation of $10 \mu \mathrm{g}$ of this child's complexes in NHS resulted in C4d levels that were $67 \%$ of the levels in the BSA-anti-BSA controls. When the complexes from children with JRA and HIV infection were incubated in $30 \%$ NHS, alternative pathway activation, as measured by production of complement cleavage fragment $\mathrm{Bb}$, was not seen (data not shown)

\section{DISCUSSION}

We used gel filtration and affinity chromatography on Protein A-Sepharose to purify high-molecular-weight IgG-containing complexes from the plasma of children with JRA and congenital HIV infection. We have shown that 1 ) these complexes are composed of IgG and IgM and/or IgA and 2) these complexes activate complement via the classic pathway in vitro.

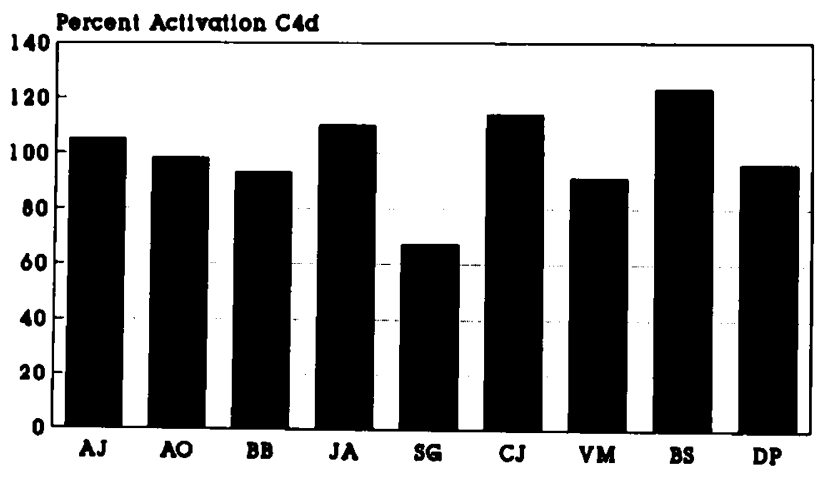

\section{BSA Ant1-BSA - 100\%}

Fig. 4. Complement activation by IgG-containing high-molecularweight fractions. Ten $\mu \mathrm{g}$ of each of the high-molecular-weight fractions were placed in $30 \%$ normal human serum at $37^{\circ} \mathrm{C}$ for $60 \mathrm{~min}$. C4d produced was then measured by ELISA and compared with a positive control consisting of BSA-anti-BSA formed at $2 \times$ antigen excess. Patients $A J, A O, B B$, and $J A$ (patients $1,4,3$, and 2, respectively) are children with JRA. Patients $S G, C J, V M, B S$, and $D P$ (patients 10, 5, 8. 7, and 9, respectively) have congenital HIV infection. 
The presence of CIC is well documented in JRA. The composition of such complexes has been described by Moore $e t$ al. $(8,9)$. Our results differ somewhat from those reported in their studies. Using radioimmunodiffusion, these authors reported IgA in only one of 14 preparations from children with JRA in one study (9) and in none of 10 in another study (8). However, their studies examined complexes isolated by affinity chromatography on anti-C $1 \mathrm{q}$ or anti-C3-Sepharose, and it seems possible that the complexes examined were different from the ones reported here. Furthermore, the immunoblotting techniques used in our studies may be more sensitive than immunodiffusion for detecting low concentrations of $\operatorname{IgA}$.

Our findings suggest that high-molecular-weight immune complexes seen in pediatric HIV infection are similar to those reported in adult AIDS-related complex/AIDS. Euler et al. (10) used laser nephelometry to characterize polyethylene glycolprecipitable immune complexes from HIV-infected adults. These authors found IgM as the principal immunoglobulin in these complexes, with less IgG and little IgA. These authors also reported that $\mathrm{C} 4$ content of these complexes decreased as IgM content increased. On the other hand, Jackson et al. (11) reported the frequent association of IgA-RF with polyethylene glycolprecipitated immune complexes of HIV-infected adults.

One noteworthy finding in these studies relates to the ability of these complexes to activate complement in vitro while apparently not having bound $\mathrm{C} 4$ in vivo. $\mathrm{C} 4 \mathrm{~d}$, measured by a sensitive ELISA, was not detected on any of the complexes separated by affinity chromatography on protein A-Sepharose. However, these same complexes were as efficient as model BSA-anti-BSA complexes formed at $2 \times$ antigen excess in activating the classic complement pathway. It is therefore interesting to speculate that there may be a tissue or vascular reservoir of IgG-containing complexes continually shed into the circulation of children with JRA and HIV infection. Although some of these complexes may have been in circulation long enough to bind complement and thus to be detected via complement fixation assays, a portion of these complexes may have been recently released into the circulation and able to be isolated before they have bound $\mathrm{C} 4$. This seems unlikely, however, because the activation of the classic pathway by immune complexes occurs very rapidly (12). Alternatively, these may represent complexes already processed by the alternative complement pathway. Complement interactions with immune complexes have been shown to involve two distinct processes (13). Immune complex solubilization, whereby large, preformed aggregates are solubilized, requires an intact alternative pathway. The prevention of immune precipitation, whereby the formation of large, insoluble aggregates during the formation of nascent immune complexes is inhibited, requires an intact classic pathway. The biologic behavior of immune complexes, including their binding to staphylococcal protein A, may differ depending upon whether these complexes interacted with the complement system by the process of solubilization or the prevention of immune precipitation (14). However, even if the complexes described here were processed by immune complex solubilization rather than the prevention of immune precipitation, this would still not explain why these complexes were then able to activate the classic pathway in vitro.

There is another explanation for why these complexes have not fixed $\mathrm{C} 4 \mathrm{~b}$ in vivo and yet are able to activate the classic pathway in vitro. All seven of the immune complex preparations tested had IgM-RF0. within them as detected by ELISA. $\mathrm{Ng}$ et al. (15) showed that IgG aggregates bearing monoclonal IgM-RF efficiently activate both $\mathrm{C} 3$ and $\mathrm{C} 4$ in vitro but bind each of these components poorly. Similarly, we have shown that IgM-RF from patients with adult rheumatoid arthritis impede the covalent binding of $\mathrm{C} 4 \mathrm{~b}$ to $\mathrm{IgG}$ within immune complexes, even when $\mathrm{C} 4$ is efficiently cleaved in the fluid phase by $\mathrm{Cl}(16)$. It is possible therefore that small amounts of $\mathrm{Cl}$ bound to these complexes either in vivo or in vitro can efficiently cleave fluidphase $\mathrm{C} 4$ without such $\mathrm{C} 4$ becoming incorporated into the immune complex.

We conclude that high-molecular-weight IgG-containing immune complexes can be found in both congenital HIV infection and JRA. These complexes appear to have a property that would be predicted from previously reported work with IgM-RF-bearing immune complexes $(15,16)$ : the ability to activate the classic complement pathway in vitro without having bound $\mathrm{C} 4$ in vivo. Therefore, the presence of such complexes in JRA and HIV plasma may explain our previous findings showing a lack of correlation between complement activation fragments and $\mathrm{Clq} /$ C3d-binding immune complexes in these diseases.

Although these data do not clearly indicate (or refute) a tissue or vascular origin for these complexes, we believe that a further understanding of the origin and composition of such complexes will provide important insights into the biology of immune complex processing and its role in such diverse diseases as HIV infection and JRA.

\section{REFERENCES}

1. Moore TL, Sheridan PW, Traycoff RB, Zuckner J, Dorner RW 1982 Immune complexes in juvenile rheumatoid arthritis: a comparison of four methods. J Rheumatol 9:395-401

2. Jarvis JN, Taylor H, lobidze M, DeJonge J, Chang S, Cohen F 1993 Complement activation and rheumatoid factor expression in children congenitallyinfected with HIV. Clin Immunol Immunopathol 67:50-54

3. Jarvis JN, Taylor H, lobidze M, Krenz M, Pousak T 1993 Complement activation and immune complexes in juvenile rheumatoid arthritis. J Rheumatol 20:114-117

4. Cassidy JT, Levinson JE, Bass JC 1986 A study of classification criteria for a diagnosis of juvenile rheumatoid arthritis. Arthritis Rheum 29:274-281

5. Jarvis JN, Pousak T, Krenz M 1992 Detection of IgM rheumatoid factors by enzyme-linked immunoabsorbant assay in children with juvenile rheumatoid arthritis: correlation with articular disease and laboratory abnormalities. Pediatrics 90:945-949

6. Lowry O, Rosenbrough N, Farr A, Randall R 1951 Protein measurement with Folin phenol reagent. J Biol Chem 193:265-272

7. Laemmli VK 1970 Cleavage of structural proteins during the assembly of the head of bacteriophage T4. Nature 22:680-685

8. Moore TL, Sheridan PW, Zuckner J, Dorner RW 1983 Separation and characterization of immune complexes containing $19 \mathrm{~S}$ IgM rheumatoid factor-lgG in juvenile rheumatoid arthritis. Arthritis Rheum 26:165-169

9. Moore TL, Dorner RW 1986 Separation and characterization of complementfixing immune complexes in juvenile rheumatoid arthritis patients. Rheumatol Int 6:49-52

10. Euler HH, Kern P, Löffler H, Dietrich M 1985 Precipitable immune complexes in healthy homosexual men, acquired immune deficiency syndrome and the related lymphadenopathy syndrome. Clin Exp Immunol 59:267-275

11. Jackson S, Tarkowski A, Collins JE, Dawson LM, Schrohenloher RE 1988 Occurrence of polymeric IgA 1 rheumatoid factor in acquired immune deficiency syndrome. J Clin Immunol 8:390-396

12. Miletic VD, Rodic BD 1984 Study of complement effects on kinetics of immune precipitation. Complement Inflamm 1:194-200

13. Schifferli J, Ng Y, Peters K 1986 The role of complement and its receptors in the elimination of immune complexes. N Engl J Med 315:488-495

14. Schifferli JA, Peters $\mathrm{K} 1983$ Immune adherence and staphylococcus protein $A$ binding of soluble immune complexes produced by complement activation. Clin Exp Immunol 54:827-833

15. $\mathrm{Ng}$ Y, Peters K, Walport M 1988 Monoclonal rheumatoid factor-IgG immune complexes: poor fixation of $\mathrm{C} 4$ and $\mathrm{C} 3$ despite efficient complement activation. Arthritis Rheum 31:99-107

16. Jarvis JN, Lockman JM, Levine RP 1993 IgM rheumatoid factor and the inhibition of the covalent binding of $\mathrm{C} 4 \mathrm{~b}$ to $\mathrm{IgG}$ in immune complexes. Clin Exp Rheum 11:135-141 